\title{
$16 S$ rRNAgene-based metagenomic analysis of the gut microbial community associated with the DUI species Unio crassus (Bivalvia: Unionidae)
}

Monika Mioduchowska, Katarzyna Zajac, Krzysztof Bartoszek, Piotr Madanecki, Jaroslaw Kur and Tadeusz Zajac

The self-archived postprint version of this journal article is available at Linköping University Institutional Repository (DiVA):

http://urn.kb.se/resolve?urn=urn:nbn:se:liu:diva-164614

N.B.: When citing this work, cite the original publication.

Mioduchowska, M., Zajac, K., Bartoszek, K., Madanecki, P., Kur, J., Zajac, T., (2020), 16S rRNAgenebased metagenomic analysis of the gut microbial community associated with the DUI species Unio crassus (Bivalvia: Unionidae), Journal of Zoological Systematics and Evolutionary Research.

https://doi.org/10.1111/jzs.12377

Original publication available at:

https://doi.org/10.1111/jzs.12377

Copyright: Wiley (12 months)

http://eu.wiley.com/WileyCDA/ 
1 16S rRNA gene-based metagenomic analysis of the gut microbial community associated

2

3

4 5

6

7 8

9

10

11

12 9 0

\section{with the DUI species Unio crassus (Bivalvia: Unionidae)}

\section{A short running title: Metagenomic analysis of bivalve gut microbiome}

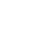

Monika Mioduchowska ${ }^{1}$, Katarzyna Zając ${ }^{2}$ (Corresponding Author, e-mail: kzajac@iop.krakow.pl), Krzysztof Bartoszek ${ }^{3}$, Piotr Madanecki ${ }^{4}$, Jarosław Kur ${ }^{5}$, Tadeusz Zając $^{2}$

${ }^{1}$ Department of Genetics and Biosystematics, Faculty of Biology, University of Gdansk, Wita Stwosza 59, 80-308 Gdańsk, Poland

${ }^{2}$ Institute of Nature Conservation, Polish Academy of Sciences, Adama Mickiewicza 33, 31120 Krakow, Poland

${ }^{3}$ Deptartment of Computer and Information Science, Division of Statistics and Machine Learning, Linköping University, Linköping 581 83, Sweden

4 Department of Biology and Pharmaceutical Botany, Faculty of Pharmacy, Medical University of Gdansk, Hallera 107, 80-416 Gdansk, Poland

${ }^{5}$ Empty Spaces Research, Miłosza 14b/3, 83-000 Pruszcz Gdański, Poland

Keywords: freshwater mussels, Unionidae, gut microbiome, next-generation sequencing (NGS), operational taxonomic units (OTUs) assignment 


\section{Abstract}

What factors determine biome richness: genetic or environmental? Sex, phylogeny, tolerance indicated by other symbionts (e.g. endosymbionts) or simply is it related to local habitat, especially if the gut biome is considered? To answer these questions, we investigated the gut microbial profile of both sexes of three Unio crassus populations, species with unique system of mitochondrial DNA inheritance called doubly uniparental inheritance (DUI), living in different ecological conditions. High throughput sequencing of the V3-V4 hypervariable regions in the bacterial $16 \mathrm{~S}$ rRNA gene fragment was performed, which resulted in a total of 1051647 reads, with 58424 reads / 65 OTUs (Operational Taxonimic Units) per sample on average. We identified a core microbiome, with all individual mussels sharing 69 OTUs (representing $23 \%$ of the total number of OTUs). Proteobacteria was the dominant phylum in all samples, followed by Firmicutes, Actinobacteria and Bacteroidetes. There were no significant differences in gut microbiome compositions between the two sexes of this species; however, we observed different phyla in geographically isolated populations. A non-metric multidimensional-scaling plot and dendrogram showed that the bacterial profile complies with the genetic structure of populations. Although we found differences in microbiomes between populations, their genetic structure suggests that the microbiome is weakly related to habitat, and more strongly to phylogeography (on both $\mathrm{F}$ and $\mathrm{M}$ mitotypes). We found no significant differences in beta diversity between the individuals of the bacterial communities measured using the Bray-Curtis index. Finally, we also examined whether OTUs were represented by symbiotic bacteria that enable cellulose digestion and by endosymbiotic bacteria that play important functions in the biology of their hosts and also affect micro-evolutionary processes and population phenomena. With regard to the endosymbionts, however, there was no relation to sex of the studied individuals, which suggests that there are no straightforward relations between DUI and microbiome. 


\section{Introduction}

In most of the Metazoa, the mitochondria, the fundamental component of the eukaryotic cell, are devoid of genetic material inherited from the male. However, in some Bivalvia there is a mechanism by which male mitochondrial DNA (M-mtDNA) can also be inherited: although both gametes supply mtDNA to the zygote, the M-mtDNA is retained only in male somatic tissues, whereas in female soma, the transferred mitochondria disappear (Guerra et al., 2017). This mechanism indicates that life with mitochondria of mixed origin is possible; however, M-mtDNA is removed in most organisms.

If for some unknown reason, a standard metazoan organism has evolved a mechanism for removing external M-mtDNA, why does it tolerate endosymbionts, despite their strong influence on host fitness by cytoplasmic incompatibility (Tram, Fredrick, Werren, \& Sullivan, 2006)? This question implies that some sort of mutual benefits for an organism and its endosymbiont may exist, the best example being the mitochondria themselves (Archibald, 2015). But the term "mutual benefits" evokes another example of widespread bacterial symbionts, their complicated interplays being under the influence of the environment (Aschenbrenner, Cernava, Berg, \& Grube, 2016). Considering that in contrast to most metazoans, DUI organisms tolerate external mtDNA, the question arises whether they are more likely to host endosymbionts. And a further question should be asked about the whole biome of such an organism: is a tolerant organism likely to have a microbiome consisting large number of bacterial taxons?

In seeking answers to these questions, one would need to study the whole bacterial biome of these organisms to see whether in organisms with DUI there are any interactions between sex (assuming males are more tolerant due to DUI), endosymbionts, microbiome and the environment. The relations with the environment would imply that possible tolerance mechanisms are subject to environmental selection and that they should indicate where to search for the relevant selection factors. As a first step one should look at the DUI-organism's microbiome and its environment.

Micro-organisms play important functions in the biology of all animals and also their micro-evolutionary processes and population phenomena. Bacteria that form animal microbiome communities ("microbiota") are ubiquitous and there is virtually no animal completely free from them. At present, studies on the microbiome profile of molluscs are still in progress, and the mechanisms that determine host-microbial associations are largely unknown, also with regard to endosymbionts (but see Mioduchowska, Zając, Zając, \& Sell 
2019). Owing to the crucial ecological and economic roles of bivalves, their health-regulating core microbial composition, which ranges from nutrient processing to protection against diseases, is of particular interest (Sweet \& Bulling, 2017). There are examples of the enormous evolutionary potential of the "mollusc - microbiome" coevolution, like bacterial chemosymbioses enabling mussels to inhabit extreme ecosystems (e.g. hydrothermal vents and cold seeps on the ocean floor) (Taylor \& Glover, 2010) or to possess unusual adaptations, like a xylotrophic ability, very rare among animals (wood consumption; Distel et al. 2011).

The thick-shelled river mussel, Unio crassus Philipsson, 1788, is a large-bodied and formerly widespread freshwater bivalve species, now threatened with extinction (Lopes-Lima et al. 2017). Results from molecular analyses suggest the existence two clades that correspond to Unio crassus crassus and to Unio crassus cf. courtillieri Hattemann, 1859, following the nomenclature applied by Prié \& Puillandre (2014). Both were found in Poland (including the studied populations; Mioduchowska, Kaczmarczyk, Zając, Zając, \& Sell, 2016) as well as in several Europaean countries (Klishko et al. 2017). The mussel has an obligatory parasitic phase during its life cycle, when larvae parasitise a fish host to complete their development; its populations are strongly diversified phylogenetically (Mioduchowska, Kaczmarczyk, Zając, Zając, \& Sell, 2016). It is also colonised by endosymbionts (Mioduchowska et al. 2019); it feeds on organic matter and microorganisms suspended in the water, indicating as yet little studied relationships with bacteria associated with habitat conditions (Aceves, Johnson, Bullard, Lafrentz, \& Arias, 2018).

Currently, next-generation sequencing (NGS) has led to rapid improvements in microbiome research, enabling an expansion of its breadth and scope over the past 20 years. NGS technology allows one to gain insight into relationships within microbial communities, including uncultured bacterial endosymbionts, that were previously unclear. Finally, metagenomic approaches have allowed us to discover and characterize a number of bacterial symbiotic relationships - from marine invertebrates to the human gut (Kennedy, Marchesi, \& Dobson 2007; Simon \& Daniel, 2011). These associations between hosts and their gutassociated bacteria are particularly underexplored in the case of freshwater mussels and in terms of potential pathogen identification (Starliper Neves, Hanlon, \& Whittington, 2008; Grizzle \& Brunners, 2009). However, a direct connection has been demonstrated with bivalve molluscs, consuming and digesting microbes (Christian, Smith, Berg, Smoot, \& Findley, 2004), and the gut microbiome could be transient and/or commensal (Harris, 1993). The relations suggesting a strong coevolution between food digestion and gut microbiome, observed in so many groups, seems to be very important. They become even more interesting 
in mussels if we consider that the gut as somatic tissue differs between the sexes with regard to DUI (Mioduchowska et al. 2016).

This study is the first report on the gut microbiome profile of $U$. crassus that uses metagenomics analysis of the V3-V4 fragment of the bacterial 16S rRNA gene. We focused on showing up differences in the hosts' microbiome composition that would indicate niche selection by bacteria for which $U$. crassus represents a favourable environment (Lokmer \& Wegner, 2015). Based on previous results of phylogeographical relationships among $U$. crassus populations from rivers in Poland which showed independent maternally (F-type) and paternally (M-type) inherited mitochondrial DNA lineages, we decided to analyse the microbiome profile of populations from very different habitats and representing different evolutionary lineages (see Mioduchowska et al. 2016).

\section{Materials and Methods}

\section{Sample Collection}

Three males and three females of $U$. crassus were sampled in 2018 from each of three rivers, differing considerably in ecological character: the Czarna Hańcza (5358'15.34"N, $23^{\circ} 18^{\prime} 12.39 " E$; northern Poland; an oligotrophic, cold, lowland river flowing through lakes in a post-glacial landscape), the Pilica (5056'36.98"N, 1950'27.81"E; central Poland; a typical, eutrophic, lowland river flowing through an agricultural landscape), and the San $\left(49^{\circ} 11^{\prime} 57.71^{\prime \prime} \mathrm{N}, 22^{\circ} 40^{\prime} 35.99^{\prime \prime E}\right.$; southern Poland; the headwater section of a large mountain river in the Carpathians, with a short period of favourable nutrition conditions for mussels). The mussels represented two lineages described by Prié \& Puillandre (2014) as well as two haplogroups observed by Mioduchowska, Kaczmarczyk, Zając, Zając, \& Sell (2016): the first clade represented by individuals from northern Poland (Unio crassus cf. courtilieri / haplogroup I) and the second clade consisted by individuals from southern Poland (Unio crassus / haplogroup II). Haplotypes from Central Poland were intermingled in both clades. Probes were collected and transported to the laboratory.

$U$. crassus is a dioecious species (Bauer, 2001). The sex of each individual was determined by gonad biopsy. Each mussel's gonad was punctured with a needle and a very small sample of gonad tissue was sucked out using a syringe. The tissue samples were examined under a microscope in order to identify the sex. The procedure enabled animals of the required sex ( $3 \widehat{\sigma}$ and $3 \stackrel{+}{)}$ ) to be collected. 
In the lab the somatic tissues of the mussels were dissected and stored at $-80^{\circ} \mathrm{C}$. Mussel tissues including the guts and hepatopancreas were used for metagenomic analysis.

162

163

164

165

166

167

168

169

170

171

172

173

\section{DNA extraction and amplicon library generation}

DNA was extracted from approximately $25 \mathrm{mg}$ of gut using silica membranes from the commercial Genomic Mini kit for universal genomic DNA isolation (A\&A Biotechnology). In addition to the protocol, we added $100 \mu 1$ of lysin solution, $0.66 \mu \mathrm{g} / \mu 1$ proteinase $\mathrm{K}$ and $0.16 \mu \mathrm{g} / \mu \mathrm{l}$ RNAse for efficient lysis of the microbial community. The incubation was performed overnight at $37^{\circ} \mathrm{C}$ and then for $2 \mathrm{~h}$ at $50^{\circ} \mathrm{C}$. To avoid cross contamination of the sample, all the laboratory procedures were conducted with sterile equipment. The extracted DNA was quantified by photometry using a NanoDrop ND-1000 UV-vis (Thermo Fisher Scientific).

Next-generation sequencing of V3-V4 hypervariable regions of the bacterial $16 \mathrm{~S}$ rRNA gene were amplified using the following universal bacterial primer set: $341 \mathrm{~F}$ ( 5 'CCTACGGGNGGCWGCAG-3') and 785R (5'-GACTACHVGGGTATCTAATCC-3') (Eiler, Heinrich, \& Bertilsson, 2012). Each library was prepared with a two-step PCR protocol based on Illumina's "16S metagenomic library prep guide" using Q5 HotStart High-Fidelity DNA Polymerase (NEBNext) and the Nextera Index kit $(2 \times 250 \mathrm{bp})$ according to the manufacturer's protocol. Pooled amplicons were sequenced using a MiSeq sequencer. Paired-end (PE) technology using Illumina v2 putty (Genomed, Poland) with the manufacturer's run protocols (Illumina, Inc., San Diego, CA, USA) was applied and pairedend reads were quality trimmed and joined with a quality threshold of 0.9 with PANDAseq v. 2.8123. All sequences that did not meet this quality criteria were removed.

\section{Taxonomic classification of the bacterial 16S rRNA gene and bioinformatic analysis}

We used the MiSeq Reporter (MSR) v. 2.6 (16S Metagenomics Protocol) for automatic de-multiplexing of raw reads and primary sequences analysis. The hclust method, v. 1.2.22q125 (Edgar, 2010) was applied to subsequently clustered next-generation reads into operational taxonomic units (OTUs), at $97 \%$ similarity. Taxonomic classifications for the next-generation reads were conducted using the Greengenes release 13.5 database as a reference (DeSantis et al., 2006) However, it is difficult to identify interspecific interactions between microbiota and parasites. Nevertheless infections have been previously linked to higher diversity of microbiome community, but the impact on 
bacterial OTUs have been parasite species specific (e.g. Baxter et al. 2015, Newbold et al. 2017).

Each probe was described by a vector that calculates the abundance of the microbiome community. This is quantified as an integer count of the number of sequences obtained for different bacterial species within the guts of $U$. crassus. Beta diversity ( $\beta$ diversity) indicex, i.e. Bray-Curtis dissimilarity matrix (Yan et al.2016), was estimated using the Explicet software package (Robertson et al., 2013). To visualize the similarity between probes we reduced the data to a 2-dimensional space through non-metric multidimensional scaling (Chapter 4.5 Everitt \& Hothorn, 2011). This was done using the isoMDS() function from the MASS (Venables \& Ripley, 2002) R package (R Core Team 2017). Then, the proximity between the microbiome composition from all the individuals tested was also presented in the form of a dendrogram, using R's hclust() function that is in the package stats found in R. Our custom PHP script (PHP Group, https://www.php.net) was applied to determine specific and shared OTUs.

The raw NGS reads were deposited under the study accession number PRJNA530367 in NCBI BioSample. All scripts are available on request.

\section{Results and Discussion}

Diet is one of the main components determining the community structure of an organism, and hosts are known to select their gut microbes selectively and/or functionally (Turnbaugh et al., 2007, Zilber-Rosenberg \& Rosenberg, 2008). To date, the microbial profiles of bivalve tissues have been analysed by means of culture-dependent methods (Garnier et al. 2007, Wendling et al. 2014); only a few studies on bivalve microbiome communities have been conducted using NGS technology (e.g. King, Judd, Kuske, \& Smith, 2012; Trabal Fernandez, Mazon-Suastegui, Vazquez-Juarez, Ascencio-Valle, \& Romero, 2014; Wegner, Volkenborn, Peter, \& Eiler, 2013; Lokmer, Kuenzel, Baines, Wegner, 2016). Here, we investigated the gut microbial composition of both sexes of six individuals from the three $U$. crassus populations living in different ecological conditions. Sequencing of the V3V4 amplicon of the 16S rRNA gene resulted in 1051647 reads, with 58424 reads / 65 OTUs per sample on average. For details, see Table 1 and Supporting Information S1.

Previous research has suggested that the host has an influence on its bacterial community structure, which helps to understand the persistence of widespread core 
microbiomes across diverse phylogenies (Fraune \& Bosch, 2007). The core microbiome of the host is defined as the microbial community present in all individuals of the species, regardless of the environment (Turnbaugh et al., 2007). Moreover, it has been observed that the bacterial phylum level is seasonally stable in mollusc gut bacterial communities, with some shifts in abundance but not diversity. Proteobacteria and its classes have been described as the most abundant members of the microbiome, regardless of the host species (e.g. Trabal Fernández et al. 2014; Cleary et al. 2015; Vezzulli et al. 2018), and this is consistent with our research. The abundance of core bacteria phyla is presented in Figure 1.

The next most common phyla were Firmicutes and Actinobacteria, although Bacteroides was also widespread - observed in all populations, though less abundant. A total of 13 bacterial phyla were identified as unique or less abundant in single individuals/populations from the three rivers (Figure 2, Supporting Information S1). There were no significant differences in gut microbiome composition between the two sexes of the target species. However, we did observe different phyla in geographically isolated populations, which is consistent with previous research on the gut microbiome of bivalves (e.g. Trabal Fernandez et al. 2014). Although both extrinsic (environmental) and intrinsic (host) factors are crucial in shaping the microbiome profile of aquatic organisms, it seems that host genetic factors may be the driving force in bacterial colonization control (Dishaw et al. 2012).

Analysis of OTU distribution in all three populations revealed that they shared a total of 69 OTUs, representing 23\% of the total number of OTUs (Figure 3). The population from the River Pilica has the most OTUs in common with the other populations investigated. In addition, each juxtaposition showed distinct differences between the microbiomes from the San and the Czarna Hańcza (Figure 3).

We generated a non-metric multidimensional-scaling plot and dendrogram to visualize the clustering patterns related to the origin of $U$. crassus based on gut OTU abundances (Figure 4). This analysis showed that the bacterial profile was consistent with the genetic structure of the populations: populations from the San (blue marks) and the Czarna Hańcza (red marks) formed two dense clusters but separate from that of the Pilica (green marks in Fig. 4). This observation is consistent with the phylogenetic relationships of these populations at mitochondrial molecular markers that clearly identified two groups of haplotypes according to $\mathrm{F}$ and $\mathrm{M}$ mitotypes. These groups comprised haplotypes found in the Czarna Hańcza (haplogroup I) and San (haplogroup II) populations, respectively. We also observed that haplotypes from the Pilica population were intermingled in both clades (Mioduchowska et al. 
2016). This is surprising from the ecological point of view, because the Pilica, a eutrophic, lowland river, is quite distinct from the other two, which are fast-flowing and oligotrophic. Trabal et al. (2012) pointed out that geographical location was the primary driver of the gut microbiome composition of bivalves. Nevertheless, the influence of random events could be another factor affecting microbiome diversity, which helps to explain differences in the microbiome profile among geographically separated organisms and may be attributed to random host- bacterial interactions (Lankau Hong, \& Mackie, 2012). In turn, beta diversity allowed for analyzing the diversity between particular assemblages. Here, the Bray-Curtis index, that measures the dissimilarity between the individuals, was applied and no significant differences was found within species (Figure 5). This is not surprising because a speciesspecific core microbiome was observed in all the samples and the microbial composition diversity was analyzed based on taxonomic abundance profiles.

It has also been shown that molluscs have a microbiota specialized in various functions, e.g. the degradation of native cellulose (Flari \& Charrier, 1992, Charrier \& Rouland, 1999). Comprehensive analysis of the U. crassus microbiome profile allowed us to find a symbiotic bacteria enabling cellulose digestion: uncultured Flavobacterium sp. (Dar, Pawar, Jadhav, \& Pandit, 2015), Stenotrophomonas sp. (Pinheiro Correa, R. F., Cunha, R. S., Cardoso, \& Chaia 2015), Bacillus sp. (Pinheiro, Correa, Cunha, Cardoso, \& Chaia, 2015) and Pseudomonas sp. (Charrier, 1990, Watkins \& Simkiss, 1990). Moreover, Chryseobacterium was found in all individuals from the River San, in two males from the Czarna Hańcza and one male from the Pilica (Van Horn et al. 2011). Evidently, considering the ubiquity of native cellulose degrading bacteria, this microbiome could be species-specific. Nevertheless, our findings were surprising because we discovered the presence of an endosymbiotic bacterium, Candidatus Xiphinematobacter, in both sexes in the Pilica population. C. Xiphinematobacter has hitherto been identified in Nematoda, in which host-endosymbiont co-evolution has been demonstrated, and the induction of parthenogenesis in their hosts also observed (Vandekerckhove, Willems, Gillis, \& Coomans, 2000). Since the mechanism of $C$. Xiphinematobacter transmission is unknown, horizontal transfer to its host cannot be ruled out. A more in-depth distribution analysis of this putative bacterial endosymbiont in $U$. crassus tissues is therefore required.

Although we have found differences in gut microbiomes between populations, their genetic structure suggests that the microbiome is weakly related to habitat, and more strongly to phylogeography. However, we did not find any relation of the endosymbionts to the sex of the individuals studied, which suggests that there are no straightforward relations between 
295 DUI and microbiome. Although complex relationships between the bivalves, their habitats 296 and microbiome profiles have been studied for 30 years, the mechanisms mediating mussel297 bacterial symbioses are still far from being explained.

298

299

300

\section{Acknowledgements}

301 This research was supported in part by Polish National Science Centre Grant No. NCN DEC302 2017/01/X/NZ8/01873. KB is supported by the Swedish Research Council's 303 (Vetenskapsrådet) grant no. 2017-04951. 


\section{References}

Aceves, A. K., Johnson, P., Bullard, S. A., Lafrentz, S., \& Arias, C. R. (2018). Description and characterization of the digestive gland microbiome in the freshwater mussel Villosa nebulosa (Bivalvia: Unionidae). Journal of Molluscan Studies, 84, 240-246. doi:10.1093/mollus/eyy014.

Archibald, J. M. (2015). Endosymbiosis and eukaryotic cell evolution. Current Biology, 25 (19), R911-R921. doi: 10.1016/j.cub.2015.07.055.

Aschenbrenner, I. A., Cernava, T., Berg, G., \& Grube, M. (2016). Understanding microbial multi-species symbioses. Frontiers in Microbiology, 7, 180. doi: 10.3389/fmicb.2016.00180.

Bauer, G. (2001). Life-History Variation on Different Taxonomic Levels of Naiads. In G. Bauer \& K. Wachtler (Eds.), Ecology and Evolution of the Freshwater Mussels Unionoida (pp 83-91). Ecological Studies, 145. Springer-Verlag: Berlin, Heidelberg.

Baxter, N. T., Wan, J. J., Schubert, A. M., Jenior, M. L., Myers, P., \& Schloss, P. D. (2015). Intra- and interindividual variations mask interspecies variation in the microbiota of sympatric Peromyscus populations. Applied and Environmental Microbiology, 81, 396- 404. doi: 10.1128/AEM.02303-14

Charrier, M. (1990). Evolution, during digestion, of the bacterial flora in the alimentary system Helix aspersa (Gastropoda:Pulmonata): A scanning electron microscope study. Journal of Molluscan Studies, 56, 425-433. doi: 10.1093/mollus/56.3.425.

Charrier, M., \& Rouland, C. (1992). The digestive osidases of the snail Helix aspersa: Localizations and variations according to the nutritional status. Canadian Journal Zoology, 70, 2234-2241.

Christian, A. D., Smith, B. N., Berg, D. J., Smoot, J. C., \& Findley, R. H. (2004). Trophic position and potential food sources of 2 species of unionid bivalves (Mollusca: Unionidae) in 2 small Ohio streams. Journal of North American Benthological Society, 23, 101-113. doi: 10.1899/0887-3593(2004)023<0101:TPAPFS>2.0.CO;2.

Cleary, B., Brito, I. L., Huang, K., Gevers, D., Shea, T., Young, S., \& Alm, E. J. (2015). Detection of low-abundance bacterial strains in metagenomic datasets by eigengenome partitioning. Nature Biotechnology, 33(10), 1053-1060. doi: 10.1038/nbt.3329.

Dar, M. A., Pawar, K. D., Jadhav, J. P., \& Pandit, R. S. (2015). Isolation of cellulolytic bacteria from the gastro-intestinal tract of Achatina fulica (Gastropoda: Pulmonata) 
and their evaluation for cellulose biodegradation. International Biodeterioration Biodegradation 98, 73-80. doi: 10.1016/j.ibiod.2014.11.016.

DeSantis, T. Z., Hugenholtz, P., Larsen, N., Rojas, M., Brodie, E. L., Keller, K., Huber, T., Dalevi, D., Hu, P., \& Andersen, G.L. (2006). Greengenes, a chimera-checked 16s rRNA gene database and workbench compatible with ARB. Applied and Environmental Microbiology, 72, 5069-5072. doi: 10.1128/AEM.03006-05

Dishaw, L. J., Flores-Torres, J. A., Mueller, M. G., Karrer, C., Skapura, D. P., Melillo, D., Zucchetti I., De Santis R., Pinto M. R., \& Litman, G. W. (2012). A basal chordate model for studies of gut microbial immune interactions. Frontiers in immunology, 3, 96. doi: 10.3389/fimmu.2012.00096.

Distel, D. L., Amin, M., Burgoyne, A., Linton, E., Mamangkey, G., Morrill, W., Nove, J., Wood, N., \& Yang, J. (2011). Molecular phylogeny of Pholadoidea Lamarck, 1809 supports a single origin for xylotrophy (wood feeding) and xylotrophic bacterial endosymbiosis in Bivalvia. Molecular Phylogenetics and Evolution, 61(2), 245-54. doi: 10.1016/j.ympev.2011.05.019.

Eiler, A., Heinrich, F., \& Bertilsson, S. (2012). Coherent dynamics and association networks among lake bacterioplankton taxa. The ISME Journal, 6, 330-342. doi: 10.1038/ismej.2011.113.

Edgar, R. C. (2010). Search and clustering orders of magnitude faster than BLAST. Bioinformatics 26, 2460-2461. doi: 10.1093/bioinformatics/btq461.

Everitt, B., \& Hothorn, T. (2011). An Introduction to Applied Multivariate Analysis with R. Springer: New York, Dordrecht, Heidelberg, London. doi: 10.1007/978-1-4419-96503.

Flari, V., \& Charrier, M. (1992). Contribution to the study of carbohydrases in the digestive tract of the edible snail Helix lucorum L. (Gastropoda: Pulmonata: Stylommatophora) in relation to its age and its physiological state. Comparative Biochemistry and Physiology, 102, 363-372. doi: 10.1016/0300-9629(92)90148-J.

Fraune, S., \& Bosch, T. C. (2007). Long-term maintenance of species-specific bacterial microbiota in the basal metazoan Hydra. Proceedings of the National Academy of Sciences, 104 (32), 13146-13151. doi: 10.1073/pnas.0703375104.

Garnier, M., Labreuche, Y., Garcia, C., Robert, M., \& Nicolas, J. L. (2007). Evidence for the involvement of pathogenic bacteria in summer mortalities of the Pacific oyster Crassostrea gigas. Microbial Ecology, 53, 187-196. doi: 10.1007/s00248-006-9061-9. 
Grizzle, J. M., \& Brunners, C. J. (2009). Infectious diseases of freshwater mussels and other freshwater bivalve mollusks. Reviews in Fisheries Science, 17: 425-467. doi: 10.1080/10641260902879000.

Guerra, D., Plazzi, F., Stewart, D. T., Bogan, A. E., Hoeh, W. R., \& Breton, S. (2017). Evolution of sex-dependent mtDNA transmission in freshwater mussels (Bivalvia: Unionida). Scientific reports, 7: 1551. https://doi.org/10.1038/s41598-017-01708-1.

Harris, J. M. (1993). The presence, nature, and role of gut microflora in aquatic invertebrates: a synthesis. Microbial Ecology, 25, 195-231. doi: 10.1007/BF00171889.

Kennedy, J., Marchesi, J. R., \& Dobson, A. D. W. (2007). Metagenomic approaches to exploit the biotechnological potential of the microbial consortia of marine sponges. Applied Microbiology and Biotechnology, 75, 11-20. doi: 10.1007/s00253-007-0875-2.

King, G. M., Judd, C., Kuske, C. R., \& Smith C. (2012). Analysis of stomach and gut microbiomes of the eastern oyster (Crassostrea virginica) from coastal Louisiana, USA. PLoS One 7, e51475. doi: 10.1371/journal.pone.0051475.

Klishko, O., Lopes-Lima, M., Froufe, E., Bogan, A., Vasiliev, L., \& Yanovich L. 2017. Taxonomic reassessment of the freshwater mussel genus Unio (Bivalvia: Unionidae) in Russia and Ukraine based on morphological and molecular data. Zootaxa, 4286 (1): 093-112. doi: 10.11646/zootaxa.4286.1.4.

Lankau, E.W., Hong, P., \& Mackie, R. I. (2012). Ecological drift and local exposures drive enteric bacterial community differences within species of Galapagos iguanas. Molecular Ecolology, 21, 1779-1788. doi: 10.1111/j.1365-294X.2012.05502.x.

Lokmer, A., Kuenzel, S., Baines, J. F., \& Wegner, K. M. (2016). The role of tissue-specific microbiota in initial establishment success of Pacific oysters. Environmental Microbiology, 18(3), 970-987. doi: 10.1111/1462-2920.13163.

Lokmer, A., \& Wegner, K. M. (2015). Hemolymph microbiome of Pacific oysters in response to temperature, temperature stress and infection. The ISME Journal, 9, 670-682. doi: 10.1038/ismej.2014.160.

Lopes-Lima, M., Sousa, R., Geist, J., Aldridge, D., Araujo, R., Bergengren, J., Bespalaja, Y., Bódis, E., Burlakovam, L., Van Damme, D., Douda, K., Froufe, E., Georgiev, D., Gumpinger, C., Karatayev, A., Kebapçi, Ü., Killeen, I., Lajtner, J., Larsen, B., Lauceri, R., Legakis, A., Lois, S., Lundberg, S., Moorkens, E., Motte, G., Nagel, K.O., Ondina, P., Outeiro, A., Paunovic, M., Prié, V., von Proschwitz, T., Riccardi, N., Rudzīte, M., Rudzītis, M., Scheder, Ch., Seddon, M., Şereflişan, H., Simić, V., Sokolova, S., Stoeckl, K., Taskinen, J., Teixeira, A., Thielen, F., Trichkova, T., 
Varandas, S., Vicentini, H., Zając, K., Zając, T., \& Zogaris, S. (2017). Conservation Status of Freshwater Mussels in Europe: State of the Art and Future Challenges. Biological Reviews, 92 (1), 572-607. doi:10.1111/brv.12244.

Mioduchowska, M., Kaczmarczyk, A., Zając, K., Zając, T., \& Sell, J. (2016). Genderassociated mitochondrial DNA heteroplasmy in somatic tissues of the endangered freshwater mussel Unio crassus (Bivalvia: Unionidae): implications for sex identification and phylogeographical studies. Journal of Experimental Zoology, 325A (9), 610-625. doi: 10.1002/jez.2055.

Mioduchowska M., Zając K., Zając T., \& Sell J. (2019). The first report on the occurrence of endosymbiotic bacteria which cause cytoplasmic incompatibility in the endangered freshwater Unio crassus (Philipsson, 1788): microbiome metagenomics. In: The 34th Polish Malacological Seminar. Seminar Report. Folia Malacologica 27 (2): 143. doi: 10.12657/folmal.027.011.

Newbold, L. K., Burthe, S. J., Oliver, A. E., Gweon, H. S., Barnes, C. J., Daunt, F., \& van der Gast, C. J. (2017). Helminth burden and ecological factors associated with alterations in wild host gastrointestinal microbiota. The ISME Journal 11, 663-675. doi: 10.1038/ismej.2016.153

Pinheiro, G. L., Correa, R. F., Cunha, R. S., Cardoso, A. M., \& Chaia, C. (2015). Isolation of aerobic cultivable cellulolytic bacteria from different regions of the gastrointestinal tract of giant land snail Achatina fulica. Frontiers in Microbiology, 6, 860. doi: 10.3389/fmicb.2015.00860.

Prié, V., \& Puillandre, N. (2014). Molecular phylogeny, taxonomy, and distribution of French Unio species (Bivalvia, Unionidae). Hydrobiologia, 735: 95. doi: 10.1007/s10750013-1571-0.

R Core Team (2017). R: A language and environment for statistical computing. R Foundation for Statistical Computing, Vienna, Austria. Retrieved from https://www.Rproject.org/.

Robertson, C. E., Harris, J. K., Wagner, B. D., Granger, D., Browne, K., Tatem, B., Feazel, L. M., Park, K., Pace, N. R., \& Frank D.N. (2013). Explicet: graphical user interface software for metadata-driven management, analysis and visualization of microbiome data. Bioinformatics 29, 3100-3101. doi: 10.1093/bioinformatics/btt526

Simon, C., \& Daniel, R. (2011). Metagenomic analyses: past and future trends. Applied and Environmental Microbiology, 77, 1153-1161. doi: 10.1128/AEM.02345-10. 
Starliper, C.E., Neves, R.J., Hanlon, S., \& Whittington, P. (2008). A survey of the indigenous microbiota (bacteria) in three species of mussels from the Clinch and Holston rivers, Virginia. Journal of Shellfish Research, 27, 1311 -1317. doi: 10.2983/0730-800027.5.1311.

Sweet, M. J., \& Bulling, M.T. (2017). On the importance of the microbiome and Pathobiome in coral health and disease. Frontiers in Marine Science, 4, 9. doi: 10.3389/fmars.2017.00009.

Taylor, J. D., \& Glover, E. A. (2010). Chemosymbiotic bivalves. In S. Kiel (Ed.), The Vent and Seep Biota (pp. 107-135), Topics in Geobiology 33. Springer: Dordrecht. doi: 10.1007/978-90-481-9572-5_5.

Trabal Fernández, N., Mazon-Suastegui, J. M., Vazquez-Juarez, R., Ascencio-Valle, F., \& Romero, J. (2014). Changes in the composition and diversity of the bacterial microbiota associated with oysters (Crassostrea corteziensis, Crassostrea gigas and Crassostrea sikamea) during commercial production. FEMS Microbiology Ecology, 88, 69-83. doi: 10.1111/1574-6941.12270.

Trabal, N., Mazon-Suastegui, J. M., Vazquez-Juarez, R., Asencio Valle, F., MoralesBojorquez, E., \& Romero, J. (2012). Molecular analysis of bacterial microbiota associated with oysters (Crassostrea gigas and Crassostrea corteziensis) in different growth phases at two cultivation sites. Microbial Ecology, 64, 555-569. doi: 10.1007/s00248-012-0039-5.

Tram, U., Fredrick, K., Werren, J., \& Sullivan, W. (2006). Paternal chromosome segregation during the first mitotic division determines Wolbachia-induced cytoplasmic incompatibility phenotype. Journal of Cell Science, 119, 3655-3663. doi: 10.1242/jcs.03095.

Turnbaugh, P. J., Ley, R. E., Hamady, M., Fraser-Liggett, C. M., Knight. R., \& Gordon, J. I. (2007). The human microbiome project. Nature, 449, 804-810. doi:10.1038/nature062.

Vandekerckhove, T. T. M., Willems, A., Gillis, M., \& Coomans, A. (2000). Occurrence of novel verrucomicrobial species, endosymbiotic and associated with parthenogenesis in Xiphinema americanum group species (Nematoda, Longidoridae). International Journal of Systematic and Evolutionary Microbiology, 50, 2197-2205. doi: 10.1099/00207713-50-6-2197.

Van Horn, D. J., Garcia, J. R., Loker, E. S., Mitchell, K. R., Mkoji, G. M., Adema, C. M., \& Takacs-Vesbach, C. D. (2011). Complex intestinal bacterial communities in three species of planorbid snails. Journal of Molluscan Studies, 78, 74-80. doi: 

10.1093/mollus/eyr038. Venables, W. N., \& Ripley, B. D. (2002). Modern Applied Statistics with S. (4th ed.). Springer: New York.

Vezzulli, L., Stagnaro, L., Grande, C., Tassistro, G., Canesi, L., \& Pruzzo, C. (2018). Comparative 16S rDNA gene-based microbiota profiles of the Pacific oyster (Crassostrea gigas) and the Mediterranean mussel (Mytilus galloprovincialis) from a shellfish farm (Ligurian Sea, Italy). Microbial Ecology, 75, 495-504. doi: 10.1007/s00248-017-1051-6. Watkins, B., \& Simkiss, K. (1990). Interactions between soil bacteria and the molluscan alimentary tract. Journal of Molluscan Studies, 56, 267-274. doi: 10.1093/mollus/56.2.267.

Wegner, K. M., Volkenborn, N., Peter, H., \& Eiler, A. (2013). Disturbance induced decoupling between host genetics and composition of the associated microbiome. BMC Microbiology, 13, 252. doi: 10.1186/1471-2180-13-252.

Wendling, C. C., Batista, F. M., \& Wegner, M. K. (2014). Persistence, seasonal dynamics and pathogenic potential of Vibrio communities from Pacific oyster hemolymph. PLoS One, 9, e94256. doi: 10.1371/journal.pone.0094256.

Yan, Q., Li, J., Yu, Y., Wang, J., He, Z., Van Nostrand, J. D., Kempher, M. L., Wu, L., Wang, Y., Liao, L., Li, X., Wu, S., Ni, J., Wang, C., \& Zhou, J. (2016). Environmental filtering decreases with fish development for the assembly of gut microbiota. Environmental Microbiology, 18(12): 4739-4754 doi.org/10.1111/1462-2920.13365

Zilber-Rosenberg, I., \& Rosenberg, E. (2008). Role of microorganisms in the evolution of animals and plants: the hologenome theory of evolution. FEMS Microbiology Reviews, 32, 723-735. doi: 10.1111/j.1574-6976.2008.00123.x. 


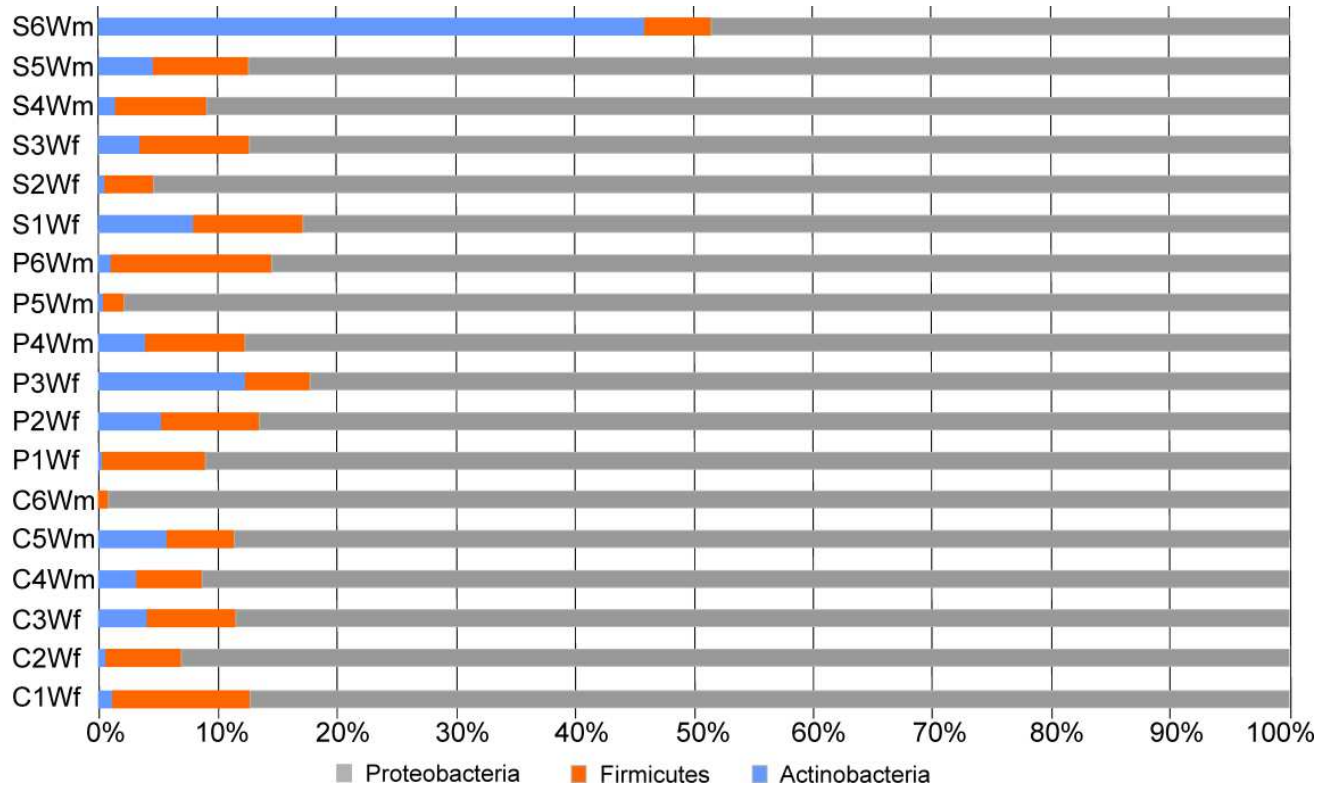

501 Figure 1 Composition of the Unio crassus gut microbiome - relative abundances of the core microbiome; P - Pilica river, C - Czarna Hańcza river, S - San river, $\mathrm{m}$ - male, f - female, W - gut, 1 - 6 - numbers of individuals.

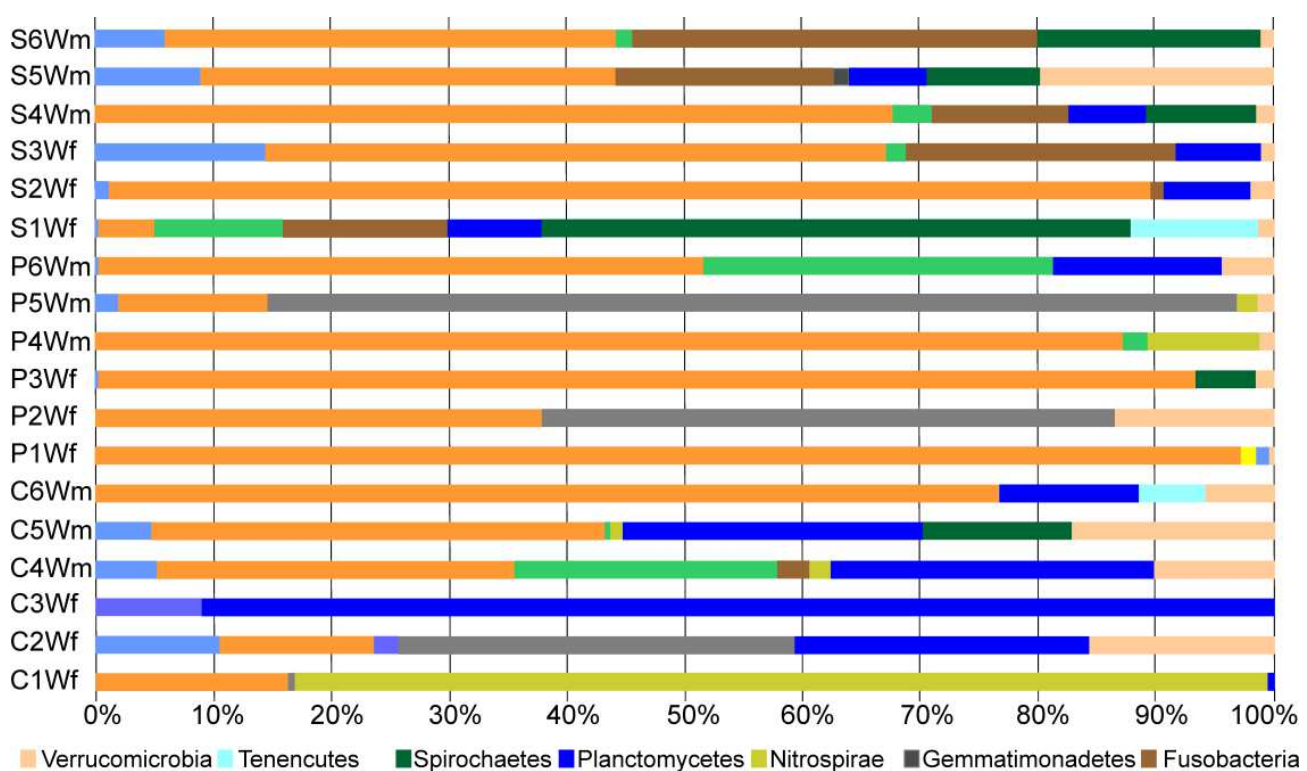

Figure 2 Composition of the Unio crassus gut microbiome - relative abundance of the microbiome that was unique or relatively less abundant; P - Pilica river, C - Czarna Hańcza 
512 Figure 3 Diagram showing the shared and unique identified OTUs in the microbiome from 513 the gut of Unio crassus.

514
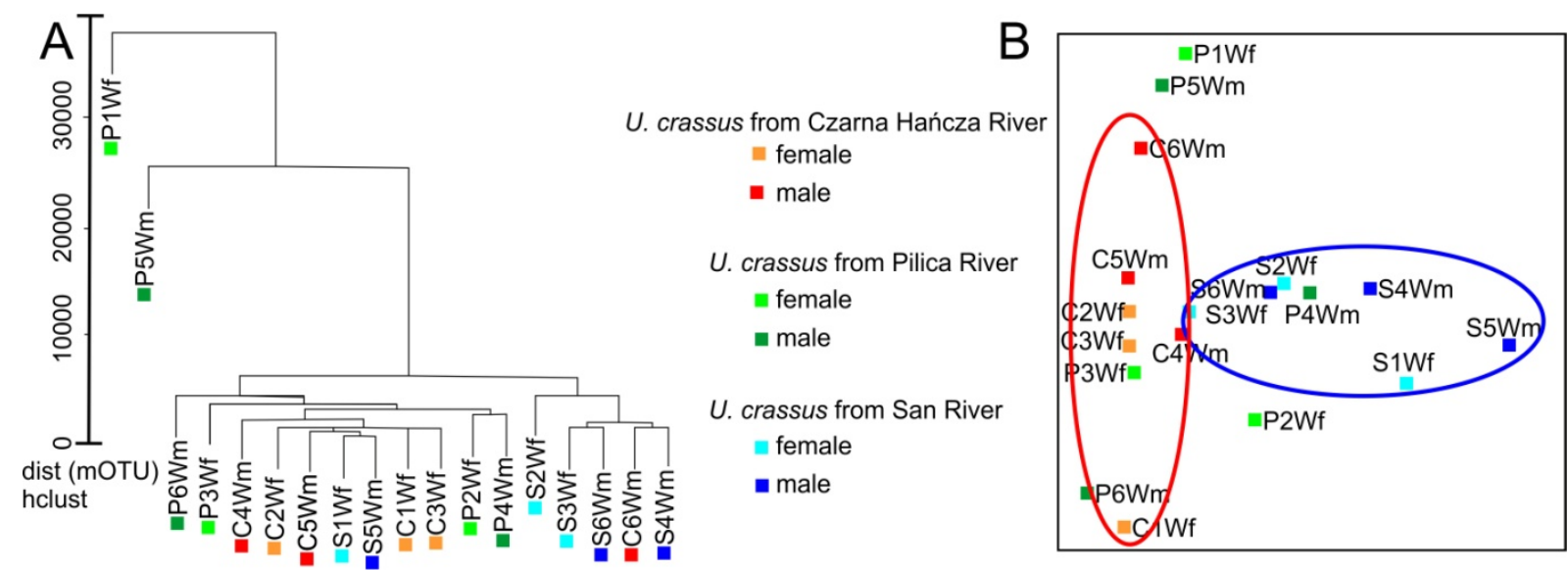

516 Figure 4 Phylogenetic relationships of Unio crassus based on OTUs in microbiome

517 compositions: A - R's hclust() dendrogram, B - non-metric multidimensional scaling of guts 518 of $U$. crassus from Polish rivers, based on percentage similarity in OTU abundances; $\mathrm{P}$ 519 Pilica river, C - Czarna Hańcza river, S - San river, m - male, f - female, W - gut, 1 - 6 520 numbers of individuals. 


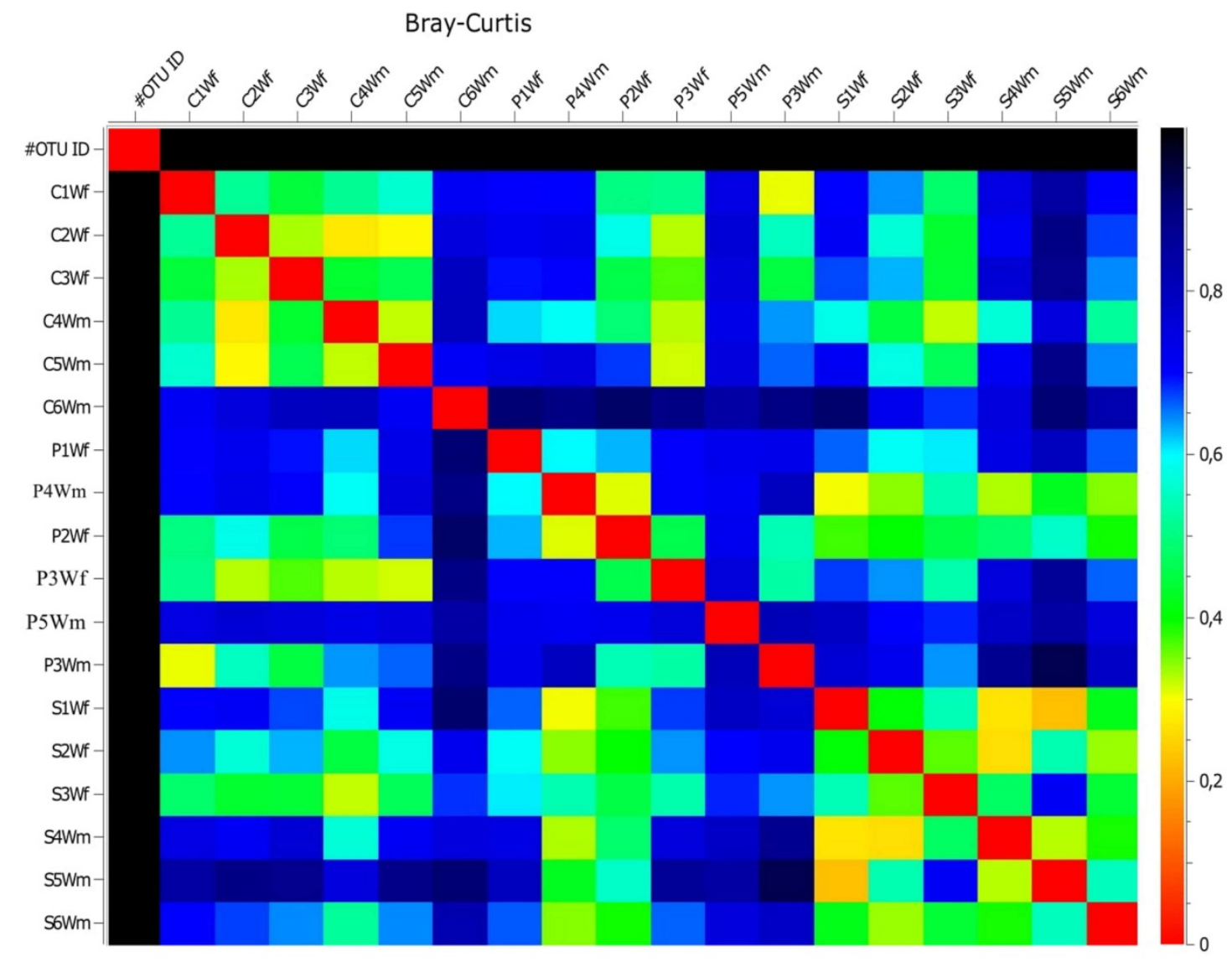

523 Figure 5 Beta-diversity of the bacterial communities measured using the Bray-Curtis index. 
526 Tables:

527 Table 1 Characteristics of the 16S rRNA gene metagenomic library.

\begin{tabular}{|c|c|c|c|c|}
\hline Rivers & $\begin{array}{c}\text { Sample ID } \\
\text { (abbreviation: } \mathrm{f}-\text { female, } \\
\mathrm{m}-\text { male) }\end{array}$ & Raw read pairs & $\begin{array}{c}\text { Reads that passed } \\
\text { quality controls }(\%)\end{array}$ & $\begin{array}{l}\text { Numer of OTUs } \\
\text { (at } 97 \% \text { identity) }\end{array}$ \\
\hline \multirow{6}{*}{$\begin{array}{l}\text { Czarna } \\
\text { Hańcza }\end{array}$} & C1Wf & 68596 & 98.93 & 47 \\
\hline & $\mathrm{C} 2 \mathrm{Wf}$ & 43894 & 98.72 & 59 \\
\hline & C3Wf & 37493 & 99.03 & 44 \\
\hline & $\mathrm{C} 4 \mathrm{Wm}$ & 60182 & 98.99 & 68 \\
\hline & C5Wm & 57955 & 98.53 & 67 \\
\hline & C6Wm & 44146 & 98.90 & 68 \\
\hline \multirow{6}{*}{ Pilica } & P1Wf & 65623 & 98.99 & 65 \\
\hline & P2Wf & 59700 & 98.83 & 42 \\
\hline & P3Wf & 57941 & 98.94 & 48 \\
\hline & $\mathrm{P} 4 \mathrm{Wm}$ & 46659 & 98.66 & 65 \\
\hline & P5Wm & 57576 & 98.82 & 120 \\
\hline & P6Wm & 60649 & 98.68 & 56 \\
\hline \multirow{6}{*}{ San } & S1Wf & 66581 & 98.86 & 57 \\
\hline & S2Wf & 72029 & 98.36 & 83 \\
\hline & S3Wf & 56009 & 98.80 & 70 \\
\hline & S4Wm & 63884 & 98.64 & 71 \\
\hline & S5Wm & 69321 & 99.03 & 72 \\
\hline & S6Wm & 63409 & 98.46 & 67 \\
\hline
\end{tabular}

528

529

530

531 
533 List of Supporting Information:

534

535 Supplementary data 1 _ OTU table 